\title{
The effect of environmental variables on soil characteristics at different scales in the transition zone of the Loess Plateau in China
}

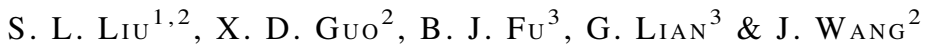 \\ ${ }^{1}$ School of Environment, State Key Laboratory of Water Environment Simulation, Beijing Normal University, Beijing 100875, ${ }^{2}$ Key \\ Laboratory of Land Use, Institute of Land Surveying \& Planning, Ministry of Land \& Resources, Beijing 100035, and ${ }^{3}$ Research \\ Center for Eco-Environmental Science, Chinese Academy of Sciences, Beijing 100085, China
}

\begin{abstract}
As a result of human disturbance and topographic variability, land use mosaics are characteristic of the transition zone of the Loess Plateau in Shaanxi Province, China. Soils are particularly sensitive to change when land degradation processes are dominant. An understanding of the influences of environmental variables is required to inform land management and agricultural production. In this study the relationships between land type, topography and soil properties were analysed for Hengshan County at two different scales using detrended canonical correspondence analysis. The results show that variations in soil properties are strongly influenced by topography, land use and vegetation. Slope, elevation and aspect are also of importance at the county and small catchment scales of analysis. Though land use type proved to be of lesser importance than topographic factors, ANOVA analysis showed that there were significant differences in soil organic matter (SOM), total nitrogen (TN), total phosphorus (TP), available nitrogen, available potassium and clay \%. Areas under vegetables had significantly higher SOM and TN content at the catchment scale. The results will enhance our ability to predict spatial and temporal changes in soils. In addition, it is shown that soil fertility could be improved by land reform and management in the hilly-gully area.
\end{abstract}

Keywords: Soil properties, land use, detrended canonical correspondence analysis, landscape, spatial variation, Loess Plateau of China

\section{Introduction}

Spatial variability in soils exists at many scales with different dominant controlling factors. An understanding of the variability and distribution of soil nutrients as influenced by site characteristics including climate, land use, landscape features and other variables is critical for assessing the effects of future land use change on soil nutrients (Kosmas et al., 2000). Soil-landscape relationships result from short and long-term pedogeomorphic processes (Gessler et al., 2000). Physical and chemical properties vary according to landscape position (Ovalles \& Collins, 1986; Miller et al., 1988) and land use (Fu et al., 1999, 2000). Land use and soil management practices influence such processes as erosion, oxidation, mineralization and soil nutrient leaching ( $\mathrm{Fu}$ et al., 1999, 2000; Hontoria et al., 1999). Slope and altitude attributes

Correspondence: S. L. Liu. E-mail: shiliangliu@yahoo.com.cn Received March 2006; accepted after revision October 2006 affect soil nutrients through controlling soil water budgets, and soil erosion and deposition (Qiu et al., 2001a; Tan et al., 2004). Soil texture, drainage and slope have been reported as explaining $51 \%$ of the variation in SOC in grassland and $54 \%$ in crop land (Burke et al., 1989), 50\% in forest mineral soils (Homann et al., 1995) and 65\% in upland forests (Grigal \& Ohmann, 1992). The effect of these variables becomes potentially more important within regions where climatic variation is not distinct.

Variation in soil nutrient status across landscapes is often analysed using such techniques as regression and geostatistical analysis (Western et al., 1998, 1999; Qiu et al., 2001b). However, these methods may not be suitable when large numbers of variables are involved. In upland gullied areas such as the Loess Plateau, landforms and landscapes have such high heterogeneity that geostatistical analysis is not effective for investigation of soil spatial variability (Zhang \& Oxley, 1994; Qiu et al., 2001b). In such situations, other multivariate methods are recommended (Zhang \& Oxley, 1994). 
Linear methods such as multivariate linear regression and linear canonical correlation analysis are widely used $(\mathrm{Fu}$ et al., 2004; Ma et al., 2004). Intrinsic methods such as principal component analysis using a single soil data set have been used (Qiu et al., 2001a). However, extrinsic methods that analyse patterns in one set of variables (environmental factors or predicators) compared to those in another set of variables (soil characteristics) would improve the predictive power of interpolation techniques. Nonlinear methods such as canonical correspondence analysis (CCA) have been demonstrated to be more robust than linear models in extracting variation in species abundance in relation to site environmental factors (Zhang \& Oxley, 1994; Qiu et al., 2001b). Moreover, this CCA has been applied in soil-environment research (Odeh et al., 1991; Qiu et al., 2001a). However, in some cases, the second axis of CCA may be the second variant of the first axis, leading to the 'arch effect' which reduces the efficiency of ordination (Hill and Gauch, 1980). Another nonlinear method which has proved to be effective is detrended canonical correspondence analysis (DCCA) (Qiu et al., 2001a). DCCA can remove the 'arch effect' and thus may improve the robustness of ordination.

Many studies related to soil variability have been carried out in the Loess Plateau region. Fu et al. (1999, 2000) elucidated land use effects on changes in soil nutrients. Qiu et al. $(2001 a, b)$ focused mainly on soil moisture variability in relation to topography and land use. Relationships between soil characteristics and site variables at different scales have been under-researched in the Loess Plateau. In order to gain a better understanding, we selected Hengshan County and within that, a small catchment as a study region; DCCA was used to analyse soil-land cover-landscape relationships. The objectives were to: (a) reveal soil variation under different land uses and to characterize the relative importance of each environmental factor (e.g. land use and topography) on soil properties; (b) compare the results of different scales and consider the implications for land use management.

\section{Materials and methods}

Study area

The Loess Plateau is located in the mid-upper reaches of the Yellow River and extends between $35^{\circ}-41^{\circ} \mathrm{N}$ and $102^{\circ}-$ $114^{\circ} \mathrm{E}$, has an area of 0.63 million $\mathrm{km}^{2}$ and a population of 82 million (He et al., 2003). The plateau is characterized by hilly terrain with an elevation between 1000 and $1600 \mathrm{~m}$ and a semi-arid climate with an annual precipitation between 400 and $600 \mathrm{~mm}$ (e.g. Tang \& Chen, 1991; Zhang et al., 2002). The area has been substantially degraded (Shi \& Shao, 2000). Hengshan, located between $36^{\circ} 31^{\prime}-37^{\circ} 20^{\prime} \mathrm{N}$ and $108^{\circ} 52^{\prime}-109^{\circ} 26^{\prime} \mathrm{E}$ in the transition zone of the Loess Plateau and covering an area of $2951 \mathrm{~km}^{2}$, is a typical area characterized by a semi-arid climate and a gullied upland loess landscape. The average annual precipitation is $562 \mathrm{~mm}$ and the mean annual temperature is $8.6^{\circ} \mathrm{C}$, but with great variability within seasons as well as between years. The area is mostly at an elevation of between 1200 and $1500 \mathrm{~m}$. Soils in Hengshan County, formed on deep and loose loess sediments, have a rather homogenous silty loamy texture and are weakly resistant to erosion. The soil is classified as a Calcic Cambisol according to the FAO-UNESCO soil classification. The soils are developed on loess but have been intensively used. The Zhujiagou catchment $\left(36^{\circ} 31^{\prime}-37^{\circ} 20^{\prime} \mathrm{N}\right.$ and $\left.108^{\circ} 52^{\prime}-109^{\circ} 26^{\prime} \mathrm{E}\right)$ is situated in the northern part of Hengshan County. The catchment has an area of $3.5 \mathrm{~km}^{2}$ and occurs at an altitude between 1000 and $1350 \mathrm{~m}$, though there is much variability (Figure 1).

The natural vegetation in the study area has been destroyed by long-term human activities. Dominant land use types are crop land, shrub land, grassland, forest and vegetables. Crops grown are mainly beans (Phaseolus valgaris), maize (Zea mays L.) and millet (Panicum miliaceum). Vegetables are mainly potatoes (Solanum tuberosum) and radish (Raphanus sativus). Land management for crop land and vegetable land includes a pre-sowing nitrogen fertilizer application of $50 \mathrm{~kg} \mathrm{ha}^{-1}$ as anhydrous $\mathrm{NH}_{3}$ and about $2000 \mathrm{~kg} \mathrm{ha}^{-1}$ of pig, goat or cattle manure or in a mixed form. The forest is dominated by Locust trees (Robinia pseudoacacia L.) but these have only been established since the policy 'change farmland to forest' was implemented in 1998. The grassland and areas of shrub are regarded as wasteland and are mainly covered by secondary vegetation as a result of grazing or firewood cutting. The grassland is mainly covered by annuals such as sweet wormwood (Artemisia annua L.), annual fleabane (Erigeron annuus Pers.) and sandy needlegrass (Stipa glareosa p. Smirn). The shrub land is mainly composed of little-leaf peashrub (Caragana microphylla) and Sandthorn (Hippophae rhamnoides L.).

\section{Soil sampling methods and processing}

In 2004, 254 locations were selected in Hengshan County and 82 in the Zhujiagou catchment respectively (Figure 1). The number of sampled sites on sloping crop land, grassland, forest, shrub land and vegetables was 44, 12, 14, 7, 5 at the catchment scale and 162, 33, 26. 1716 at the county scale. Surface soil samples $(0-20 \mathrm{~cm})$ were collected to determine soil organic matter (SOM), total nitrogen (TN), total phosphorus (TP), total potassium (TK), available nitrogen (AN), available phosphorus (AP), available potassium (AK), $\mathrm{pH}$, water content and soil texture. In addition, land use type, vegetation cover and slope, aspect and location of each sample site were recorded. SOM was determined by the $\mathrm{K}_{2} \mathrm{Cr}_{2} \mathrm{O}_{7}$ titration method after digestion (Nelson \& Sommers, 1975). TN was determined by the semi-micro Kjeldahl method and TP by colorimetry after wet digestion with $\mathrm{H}_{2} \mathrm{SO}_{4}$ and $\mathrm{HClO}_{4}$ (Parkinson \& Allen, 1975). AN was determined by 


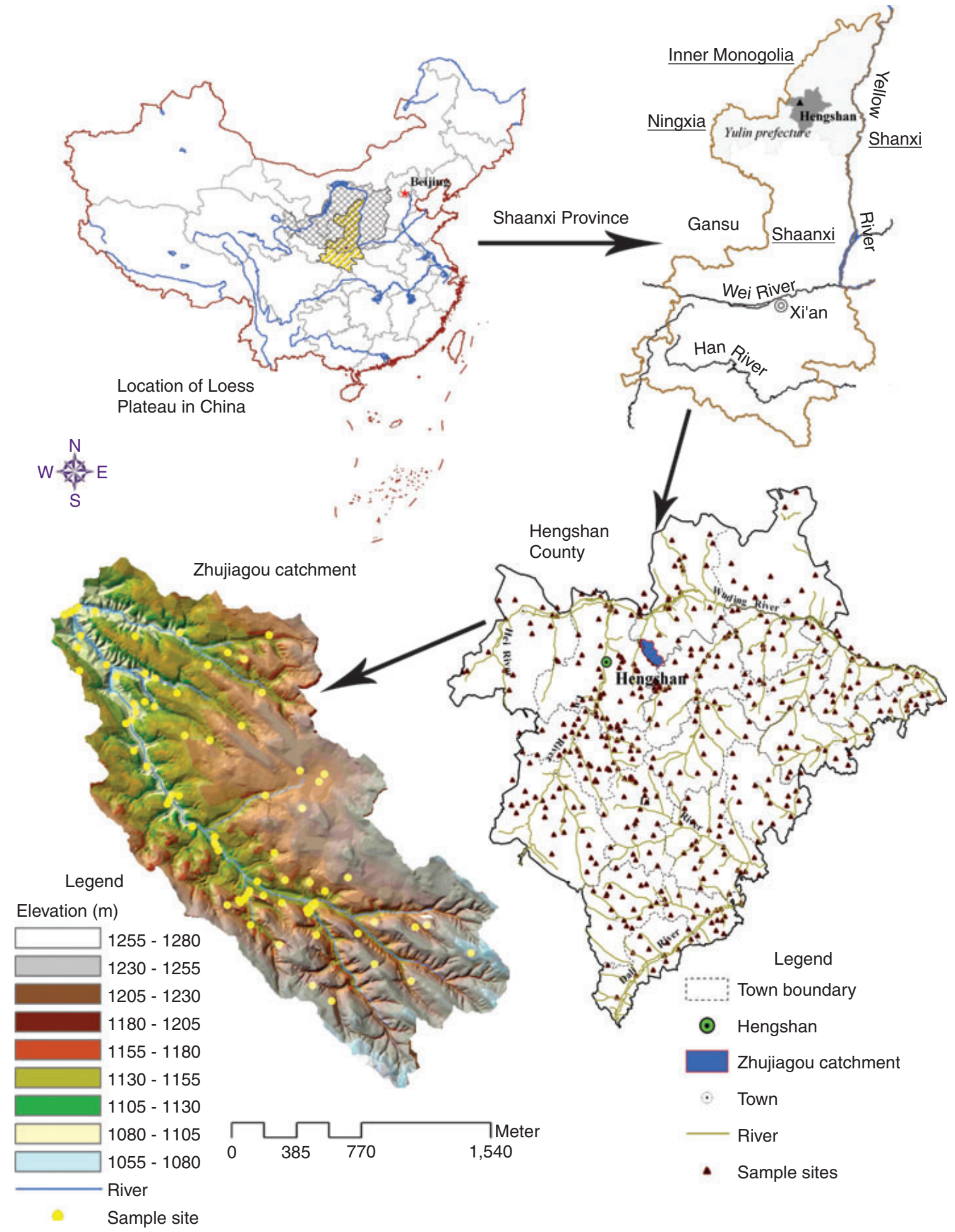

Figure 1 Location of the study area and spatial distribution of soil sampling sites.

the Cornfield method (alkaline hydrolysable nitrogen) (Liu, 1996). AP and AK were extracted with a $3 \%\left(\mathrm{NH}_{4}\right)_{2} \mathrm{CO}_{3}$ solution. After filtration, the solution was measured by ICPAES (Liu, 1996). TK was determined by atomic absorption spectrometry (Liu, 1996). Time domain reflectometry was used to measure soil moisture. Soil texture was determined using a Bouyoucos hydrometer in a soil suspension of $50 \mathrm{~g}$ of soil in $1 \mathrm{~L}$ of $\mathrm{H}_{2} \mathrm{O}$. To improve the precision of the 
results, every sample was analysed three times and an average calculated.

\section{Statistical methods}

We used DCCA for direct gradient analysis as we were mainly interested in the relationships between soil characteristics and influencing factors. Qualitative data have to be coded before analysis. We used dummy variables (presence or absence) to represent the five land use types. Aspect was recorded by degrees from north and the results were transformed using the cosine function. The data were then standardized $[0,1]$ using the extreme value standardization method (Fu et al., 2004). Slope $\left({ }^{\circ}\right)$, elevation (m) and vegetation cover $(\%)$ were expressed as measured values. The software program Canoco 4.0 was used for data processing (Centre for Biometry Wageningen, 1998). Monte Carlo permutation tests were conducted to assess the effectiveness of the canonical axis in showing these relationships and to determine the significance of a specific attribute. One-way analyses of variance (ANOVAs) procedures were used to compare the effects of different site variables on soil properties between land uses. The ANOVA analysis was conducted using the SAS program (SAS Institute, 2001).

\section{Results and discussion}

\section{Soil property variation under different land uses at different scales}

There were statistically significant differences in SOM, TN, $\mathrm{TP}, \mathrm{AN}, \mathrm{AP}$ and clay content between the five land use types (Table 1). Significance differences were found in TN and TP between land uses at the $1 \%$ level at the county scale, but at the $5 \%$ level for the catchment scale. At the catchment scale, land under vegetables had the greatest SOM and TN contents whilst at the county scale, the largest values occurred in crop land soils. Land under vegetables had the largest AN and clay contents at both scales. Moreover, the sequences from high to low values in order of soil properties were different at the two scales. SOM, TN, TP, TK, AN, AP, AK of the soils under all land uses in this region are very low compared with other areas in China. For the loessic soil, soil texture, especially clay content, has a significant influence on the SOM. Clay can store more organic matter by forming humus-clay complexes with organic matter (Tang \& Chen, 1991). Reduction in clay content, for example from erosion, results in the loss of SOM.

The variation in soil properties implies an effect of land use on nutrient distribution. The study area lies near the transition zone from the Loess Plateau to the sandy region. The SOM very much depends on additions such as returned vegetable material or organic manure. Higher soil nutrient contents in the vegetable land and crop land sug-

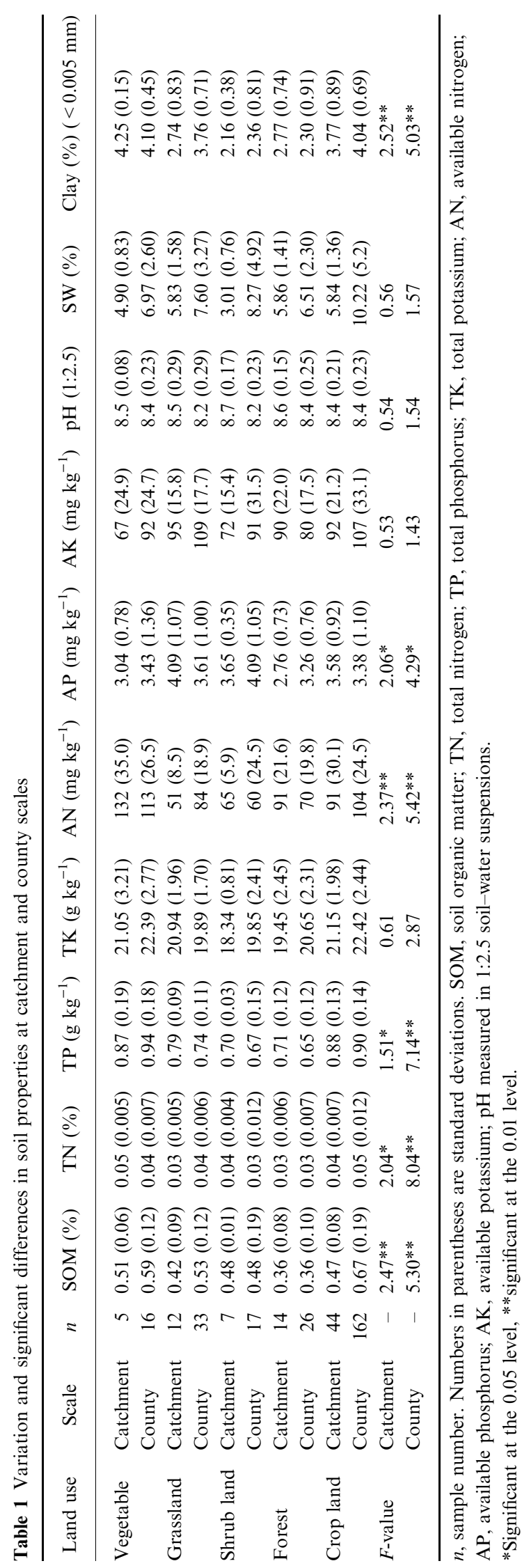


gest that local tillage with organic matter application improves land quality. Furthermore, the lower SOM contents in grassland, shrub land and forestsoils can be attributed to the fact that these land uses are usually sited on slopes with good drainage and low susceptibility to erosion whilst cultivated land occurs mainly in areas of soil deposition. In the Loess Plateau, the cultivation of sloping land is a major factor associated with soil and water erosion (Shi \& Shao, 2000). However, the smallest levels of soil nutrients were found in forest soils. Reforestation can degrade or improve soil fertility in various ways and there has been little consistent scientific evidence (Binkley, 1995). Since the introduction in 1998 of the policy of 'change farmland to forest,' large areas of crop land have been transformed to afforested land but the decrease in soil fertility has been overlooked.

\section{DCCA analysis and scale comparison}

Many authors have used DCCA or CCA to investigate the effect of environmental variables on soils (Qiu et al., 2001a; Elke et al., 2004). The results from DCCA can be displayed in an ordination diagram in which scores of soil variables are represented by points. Scores for the environmental attributes are indicated as arrows (Figure 2). In interpreting the ordination diagram, each of the arrows representing an environmental attribute gives a direction or axis of variation in relation to the two canonical ordination axes (usually the first two axes that are extracted from the soil variables as linear combinations of environmental attributes). Arrows can be extended in both directions and perpendicular lines drawn from the soil variable points. The order in which the projected points relate to the environmental axis indicates the relative importance or ranking of the weighted means of variables with respect to the attributes (Qiu et al., 2001a).

Figure 2 shows the ordination of soil properties related to environmental variables at the catchment and county scales. It is clear that land use type and topography influence soil properties. At the catchment scale, the first ordination axis represents mainly the topographic influence and the second the land use effect on soil properties (Figure 2a). At the county scale, the first ordination axis represents the effect of land use (Figure 2b). The effects of land use or topography on soil characteristics are different at the two scales. For example, AN exhibited the highest score at the catchment scale and soil moisture (SW) was next. At the county scale, AP and SOM have higher scores than the other soil properties. At the small catchment scale, SOM, TN and clay content have negative relationships with slope while they are positively correlated with crop land and vegetable land. At the county scale, there are more complicated relationships between soil and its influencing factors. AN, AK, SW and clay content correlate negatively with slope and positively with crop land and vegetation cover. However, there are some consistent results between the two scales. For example, AP relates positively to slope, grassland and shrub land. The results suggest that the variability in these properties is highly spatially dependent.

Table 2 gives the coefficients of correlation between DCCA ordination axes and mean and standard deviation of environmental attributes (land use and topography). The cumulative percentage variance of soil-environment relationships shows that the first and second axis is $69 \%$ and $98 \%$ at the catchment and county scales respectively. Monte Carlo permutation tests confirmed the overall significance of the canonical ordination $(P<0.01)$ and the significance of the first axes $(P<0.01)$ (Table 2$)$. This confirms that both axes jointly represent soil distribution as determined from the DCCA ordination (Figure 2).

For the different environmental variables, slope, aspect and elevation may have more impact on soil properties than land use, but their effect varies according to scale. At the
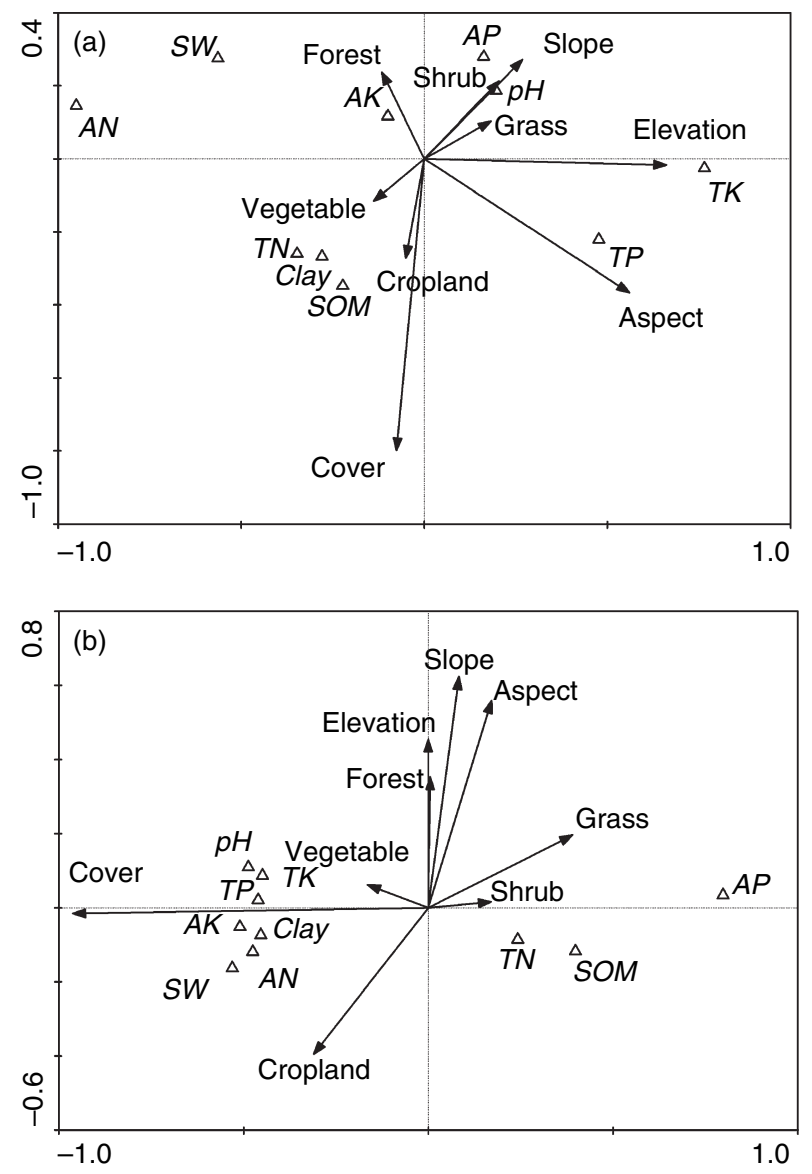

Figure 2 Ordination diagram resulting from DCCA on soil characteristics with environmental attributes at (a) catchment and (b) county scales. AP, available phosphorus, AN, available nitrogen, $\mathrm{AK}$, available potassium, TP, total phosphorus, TN, total nitrogen, TK, total potassium, SW, soil moisture, SOM, soil organic matter. 
Table 2 Coefficients of correlation between DCCA axes, mean environmental attributes and SD

\begin{tabular}{|c|c|c|c|c|c|}
\hline Environmental variables & Scale & Mean & SD & Axis 1 & Axis 2 \\
\hline \multirow[t]{2}{*}{ Elevation (m) } & Catchment & 1160.17 & 50.37 & 0.234 & -0.006 \\
\hline & County & 1150.41 & 95.24 & 0.000 & 0.160 \\
\hline \multirow[t]{2}{*}{ Aspect } & Catchment & - & - & 0.511 & -0.335 \\
\hline & County & - & - & 0.139 & 0.455 \\
\hline \multirow[t]{2}{*}{ Slope $\left(^{\circ}\right)$} & Catchment & 15.13 & 8.27 & 0.151 & 0.153 \\
\hline & County & 13.22 & 8.79 & 0.058 & 0.430 \\
\hline \multirow[t]{2}{*}{ Crop land } & Catchment & - & - & -0.040 & -0.216 \\
\hline & County & - & - & -0.226 & -0.288 \\
\hline \multirow[t]{2}{*}{ Grassland } & Catchment & - & - & 0.471 & 0.269 \\
\hline & County & - & - & 0.827 & 0.415 \\
\hline \multirow[t]{2}{*}{ Forest } & Catchment & - & - & -0.271 & 0.558 \\
\hline & County & - & - & 0.018 & 1.194 \\
\hline \multirow[t]{2}{*}{ Shrub land } & Catchment & - & - & 1.014 & 1.060 \\
\hline & County & - & - & 0.890 & 0.084 \\
\hline \multirow[t]{2}{*}{ Vegetable land } & Catchment & - & - & -0.521 & -0.437 \\
\hline & County & - & - & -0.726 & 0.274 \\
\hline \multirow[t]{2}{*}{ Vegetation cover $(\%)$} & Catchment & 0.449 & 0.275 & -0.044 & -0.460 \\
\hline & County & 0.496 & 0.241 & -0.715 & -0.012 \\
\hline \multirow[t]{2}{*}{ Cumulative $\%$ variance } & Catchment & - & - & 53.5 & 69.0 \\
\hline & County & - & - & 95.9 & 97.9 \\
\hline
\end{tabular}

DCCA, detrended canonical correspondence analysis; SD, standard deviation. small scale, elevation shows the largest effect whilst slope is more important at the larger scale. Slope is a dominant factor that influences soil erosion and soil nutrient loss. In the Loess Plateau, many researchers have shown that soil fertility varies inversely with slope (Qiu et al., 2001a). Our results are consistent with previous findings as soil properties such as SOM and TN decrease with increasing gradient. Aspect influences evapotranspiration and receipt of solar radiation. High temperature promotes SOM decomposition, thus soils usually have lower SOM content and lower fertility on slopes which are more exposed to the sun. Reid (1973), Famiglietti et al. (1998), Western et al. (1999) and Qiu et al. (2001a) reported that soil moisture content is inversely proportional to position and relative elevation. Pierson \& Mulla (1990) found that soils on foot slopes and toe slopes had a higher SOM content and greater aggregate stability than those on summit positions. In general, our results showed that soil water content and soil nutrient levels correlate negatively with elevation at both scales in the region. Greater nutrient contents on the lower elevations may result from nutrient enhancement derived from upper slopes.

The ordination diagrams suggest that crop land mainly occurs on gentle slopes whilst grassland and shrub land are more on the intermediate and comparatively steep slopes at both scales. Though land use types have lower scores in the ordination diagrams, vegetation cover has a higher score and seems to have a larger effect on soil properties at both scales. On the Loess Plateau, sufficient plant cover can reduce soil erosion before the start of the rainy season. Moreover, surface straw has the effects of reducing evaporation and retain- ing soil quality. Forest shows a negative correlation with most soil properties at both scales and the results confirm that reforestation in the study region may cause soil degradation. Furthermore, the grassland and shrub land show less effect on soil properties than the crop land.

Many authors have found that land use is affected by topography, climate and elevation. Pan et al. (1999) emphasized a physical determinism behind land use patterns. Chen et al. (2001) found strong impacts of slope on land use, but only a weak influence of aspect. In the Loess Plateau, land use structure was also affected by human factors, such as distance from villages, access difficulty or proximity to roads as well as by socio-economic and policy forces ( $\mathrm{Fu}$ et al., 2000; Zhang et al., 2004). Besides the important influence of socioeconomic factors, land cover changes in the study areas took place within the relatively stable physical constraints of the landscape. Topography as an inherent factor of soil formation also influences potential land use, though land use also has potential for modifying soil properties. In the study region, slope, land use and cover are also major factors in influencing soil fertility, so terrace construction, strip cropping and other land use rearrangements are needed to foster soil improvement. On the Loess Plateau, legume-based rotation systems such as pea-winter wheat-winter wheat-millet can help to overcome the problem of micronutrient deficiencies (Wei et al., 2006). In addition, rational and reorganized land use structures are needed on slopes to retain soil fertility. Fu et al. (1999) indicated that sloping farmland-grasslandforest or terrace-grassland-forest from valley floors to hill summits have a better capacity to maintain soil nutrients. 


\section{Conclusions}

Field investigation and subsequent statistical analysis have determined relationships between landscape features, land use types and soil properties in an upland gullied area in the Loess Plateau. Variations in soil characteristics at two scales were studied at 82 locations in a small catchment and at 254 at a county level. Significant differences for major soil properties such as SOM, TN, TP, AN, AP and \% clay between land uses were found. Land under vegetables has the highest SOM and TN content at the catchment scale whilst this applies to crop land at the county scale. Further investigation using DCCA established spatial correlations between environmental variables including slope, elevation, aspect and soil properties. The results also demonstrate that soil variations are not random. Vegetation cover and crop land have a large effect on soil properties. Soil properties have positive or negative correlations with slope, aspect and elevation. Overall there are similarities at the two scales in the effects of landscape parameters on soils and the results indicate that landscape attributes have a strong influence on particular soil properties; land improvements such as terrace construction and alternation of cropping systems provide ways to improve soil fertility.

\section{Acknowledgements}

The project was supported by the National Natural Science Foundation of China (No. 40504067, 40201004, 40321101) and Open Foundation of Key Laboratory of Land Use, Institute of Land Surveying \& Planning, Ministry of Land \& Resources. The authors wish to acknowledge team members for help with vegetation recording and soil sampling.

\section{References}

Binkley, D. 1995. The influence of tree species on forest soils processes and patterns. In: Proceedings of the Trees and Soils Workshop (eds D.J. Mead \& I.S. Cornforth), pp. 1-34. Lincoln University Press, New Zealand.

Burke, I.C., Yonker, C.M., Parton, W.J., Cole, C.V., Flach, K. \& Schimel, D.S. 1989. Texture, climate, and cultivation effects on soil organic matter content in US grassland soils. Soil Science Society of America Journal, 53, 800-805.

Centre for Biometry Wageningen 1998. Canoco for Windows 4.0. Wageningen, The Netherlands.

Chen, L.D., Wang, J., Fu, B.J. \& Qiu, Y. 2001. Land-use change in a small catchment of northern Loess Plateau, China. Agriculture Ecosystems and Environment, 86, 163-172.

Elke, H., Rainer, W. \& Annette, O., 2004. Analysing land-cover changes in relation to environmental variables in Hesse, Germany. Landscape Ecology, 19, 473-489.

Famiglietti, J.S., Rudnicki, J.W. \& Rodell, M. 1998. Variability in surface moisture content along a hillslope transect: Rattlesnake Hill, Texas. Journal of Hydrology, 210, 259-281.
Fu, B.J., Ma, K.M., Zhou, H.F. \& Chen, L.D. 1999. The effect of land use structure on the distribution of soil nutrients in the hilly area of the Loess Plateau, China. Chinese Sciences Bulletin, 44, 732-736.

Fu, B.J., Chen, L.D., Ma, K.M., Zhou, H.F. \& Wang, J. 2000. The relationships between land use and soil conditions in the hilly area of the Loess Plateau in northern Shaanxi, China. Catena, 39, 69-78.

Fu, B.J., Liu, S.L., Ma, K.M. \& Zhu, Y.G. 2004. Relationships between soil characteristics, topography and plant diversity in a heterogeneous deciduous broad-leaved forest near Beijing, China. Plant and Soil, 261, 47-54.

Gessler, P.E., Chadwick, O.A., Chamran, F., Althouse, L. \& Holmes, K. 2000. Modeling soil-landscape and ecosystem properties using terrain attributes. Soil Science Society of America Journal, 64, 2046-2056.

Grigal, D.G. \& Ohmann, L.F. 1992. Carbon storage in upland forestland of the Lake States. Soil Science Society of America Journal, 56, 935-943.

He, X., Li, Z., Hao, M., Tang, K. \& Zheng, F. 2003. Down-scale analysis for water scarcity in response to soilwater conservation on Loess Plateau of China. Agriculture, Ecosystems and Environment, 94, 355-361.

Hill, M.O. \& Gauch, H.G. 1980. Detrended correspondence analysis, an improved ordination technique. Vegetatio, 42, 47-58.

Homann, P.S., Sollins, P., Chappell, H.N. \& Strangenberger, A.G. 1995. Soil organic carbon in a mountainous, forested region: relations to site characteristics. Soil Science Society of America Journal, 59, 1468-1475.

Hontoria, C., Rodríguez-Murillo, J.C. \& Saa, A. 1999. Relationships between soil organic carbon and site characteristics in Peninsular Spain. Soil Science Society of America Journal, 63, 614-621.

Kosmas, C., Gerontidis, S. \& Marathianou, M. 2000. The effect of land use change on soils and vegetation over various lithological formations on Lesvos (Greece). Catena, 40, 51-68.

Liu, G.S. 1996. Soil physical and chemical analysis and description of soil profiles. Beijing: China Standards Press (in Chinese).

Ma, K.M., Fu, B.J., Liu, S.L., Guan, W.B., Liu, G.H., Lu, Y.H. \& Anand, M. 2004. Multiple-scale soil moisture distribution and its implications for ecosystem restoration in an arid river valley, China. Land Degradation and Development, 15, 75-85.

Miller, P.M., Singer, M.J. \& Nielsen, D.R. 1988. Spatial variability of wheat yield and soil properties on complex hills. Soil Science Society of America Journal, 52, 1133-1141.

Nelson, D.W. \& Sommers, L.E. 1975. A rapid and accurate method for estimating organic carbon in soil. Proceedings of the Indiana Academy of Science, 84, 456-462.

Odeh, I.O.A., Chittleborough, D.J. \& McBratney, A.B. 1991. Elucidation of soil-landform interrelationships by canonical ordination analysis. Geoderma, 49, 1-32.

Ovalles, F.A. \& Collins, M.E. 1986. Soil-landscape relationships and soil variability in north central Florida. Soil Science Society of America Journal, 50, 401-408.

Pan, D., Domon, G. \& de Blois, S. 1999. Temporal (1958-1993) and spatial patterns of land use changes in Haut-Saint-Laurent (Quebec, Canada) and their relation to landscape physical attributes. Landscape Ecology, 14, 35-52. 
Parkinson, J.A. \& Allen, S.E. 1975. A wet oxidation procedure suitable for determination for nitrogen and mineral nutrients in biological material. Communications in Soil Science and Plant Analysis, 6, $1-11$.

Pierson, F.B. \& Mulla, D.J. 1990. Aggregate stability in the Palouse region of Washington: effect of slope position. Soil Science Society of America Journal, 54, 1407-1412.

Qiu, Y., Fu, B.J., Wang, J. \& Chen, L.D. 2001a. Soil moisture variation in relation to topography and land use in a hillslope catchment of the Loess Plateau, China. Journal of Hydrology, 240, 243-263.

Qiu, Y., Fu, B.J., Wang, J. \& Chen, L.D. 2001b. Spatial variability of soil moisture content and its relation to environmental indices in a semi-arid gully catchment of the Loess Plateau, China. Journal of Arid Environments, 49, 723-750.

Reid, I. 1973. The influence of slope orientation upon the soil moisture regime, and its hydrogeomorphological significance. Journal of Hydrology, 19, 309-321.

SAS Institute, 2001. SAS user's guide, release 8.2. SAS Institute, Cary, NC.

Shi, H. \& Shao, M.G. 2000. Soil and water loss from the Loess Plateau in China. Journal of Arid Environments, 45, 9-20.

Tan, Z.X., Lal, R., Smeck, N.E. \& Calhoun, F.G. 2004. Relationships between surface soil organic carbon pool and site variables. Geoderma, 121, 187-195.
Tang, K.L. \& Chen, Y.Z. 1991. Characteristics and control of soil losses in the Loess Plateau region. China Science \& Technology Press, Beijing (in Chinese).

Wei, X.R., Hao, M.D., Shao, M.A. \& Gale, W.J. 2006. Changes in soil properties and the availability of soil micronutrients after 18 years of cropping and fertilization. Soil \& Tillage Research, 91, 120-130.

Western, A.W., Blöschl, G. \& Grayson, R.B. 1998. Geostatistical characteristics of soil moisture patterns in the Tarrawarra catchment. Journal of Hydrology, 205, 20-37.

Western, A.W., Grayson, R.B., Bloschl, G., Willgoose, G.R. \& McMahon, T.A. 1999. Observed spatial organization of soil moisture and its relation to terrain indices. Water Resources Research, 35, 797-810.

Zhang, J. \& Oxley, R.R.B. 1994. A comparison of three methods of multivariate analysis of upland grasslands in North Wales. Journal of Vegetation Science, 5, 71-76.

Zhang, Y., Zhan, D.R. \& Qin, H.R. 2002. Investigation into the utilization status of slope cultivated lands and the countermeasures of reasonable exploitation. Research of Soil and Water Conservation, 9, 62-66 (in Chinese with English abstract).

Zhang, Q.J., Fu, B.J., Chen, L.D. \& Zhao, W.W. 2004. Dynamics and driving factors of agricultural landscape in the semiarid hilly area of the Loess Plateau, China. Agriculture, Ecosystems and Environment, 103, 535-543. 